\title{
Analysis of Tomographic Images of the Soil Pore Space Structure by Integral Geometry Methods
}

\author{
T. G. Kalnin ${ }^{a, ~ *, ~ D . ~ A . ~ I v o n i n ~}{ }^{a}$, K. N. Abrosimov ${ }^{b}$, E. A. Grachev ${ }^{a}$, and N. V. Sorokina ${ }^{a}$ \\ ${ }^{a}$ Lomonosov Moscow State University, Leninskie Gory 1, Moscow, 119991 Russia \\ ${ }^{b}$ Dokuchaev Soil Science Institute, Pyzhevskii per. 7, Moscow, 119017 Russia \\ *e-mail: kremor1994@gmail.com \\ Received February 6, 2021; revised March 17, 2021; accepted April 7, 2021
}

\begin{abstract}
The technique of numerical analysis of three-dimensional tomographic images of the pore space of soil objects has been used in this paper. It applies methods of integral geometry, topology and morphological analysis. To characterize quantitatively the transformation of the pore space structure, tomographic images of four undisturbed soils were analyzed, i.e., heavy loamy agro-gray soil (Retic Phaeozem), agromineral (Sapric Rheic Mineralic Histosols), and hypnum (brown moss Sapric Rheic Histosols) peat soils in dry and wet conditions. For samples of the subplow horizon in agro-gray soil, a decrease in both Betty numbers was observed on wetting, where the zero number $\left(b_{0}\right)$ stands for the amount of topologically simple closed pores, and the first number $\left(b_{1}\right)$ indicates a decrease in pore connectivity, which varies in a narrower range of pore sizes as compared to $b_{0}$. When a sample of agromineral peat soil is moistened, the Euler-Poincaré characteristic is negative in the pore range of $0.1-0.16 \mathrm{~mm}$, which points to the predominating complicated branched structure of the pore space and high pore connectivity. When hypnum moss is saturated, a lot of tunnel pores get narrower ("collapse"), and the connectivity decreases due to the structural specifics of longstemmed plant residues. The number of pores and connections between them in peat soils is an order of magnitude higher than those in the subplow horizon A of the agro-gray soil. The provided quantitative changes in the considered parameters of tomographic images of the soil pore space confirm the possibility of applying them for estimating the transformation of the pore space in soils.
\end{abstract}

Keywords: soil porosity, Minkowski functional, Betti numbers, the Euler-Poincaré characteristic, computed tomography, Phaeozem (Albic), Sapric Rheic Histosol

DOI: $10.1134 /$ S1064229321090039

\section{INTRODUCTION}

Soil porosity is a three-dimensional structure with a complicated geometry of the internal surface. This $3 \mathrm{D}$ matrix of pore space as well as the shape of the boundary between the pore-solid-phase skeleton phase control in many respects the mechanical and hydrological parameters of soils. Computed tomography permits obtaining high-detailed data on the structure of soil pore space without sample destruction. However, application of different methods most often related to a quantitative analysis of $3 \mathrm{D}$ images is required for obtaining quantitative information about the pore structure.

There are many examples of analyzing 2D and $3 \mathrm{D}$ images of soils and rocks using statistical, morphological and other procedures. These methods have advantages and disadvantages of their own, far from all of them being substantiated physically $[1,3]$. Therefore, this work considers tools based on fundamental basis, i.e., statistical physics, integral geometry and topology. Minkowski functionals are four basic geometric and topological characteristics that are related to a three-dimensional object in order to describe its structure, and via an accuracy factor correspond to the pore volume, the pore surface area and the integral mean curvature of pore-solid skeleton phase boundary. The Euler-Poincaré index of the complex (convex/concave) porous space is also used, which is taken as an integral characteristic of a porous body complexity [34].

Researches are known on the application of integral geometry methods and morphological analysis to the investigation of media with complex internal structure. Thus, early works investigated artificially generated media [11, 29] and two-dimensional rock sample slices [10]; whereas, later works considered three-dimensional tomographic [18, 33, 35] and FIB-SEM images [15]. In particular, paper [35] discusses an approach to the numerical description of the internal geometry of soil samples subjected to various kinds of processing based on the analysis of the evolution of Minkowski functionals upon dilatation of both the solid phase and the pore space. It is worth noting that the methods are applicable to objects at all possi- 
Table 1. Some physical properties of peat soils

\begin{tabular}{c|r|c|c|c|c}
\hline \multirow{2}{*}{ Soil } & \multirow{2}{*}{ Depth, cm } & \multicolumn{2}{|c|}{ Density, $\mathrm{g} / \mathrm{cm}^{3}$} & Decomposition degree & Ash content \\
\cline { 3 - 6 } & & natural & experimental & \multicolumn{2}{|c}{$\%$} \\
\hline \multirow{2}{*}{ Agromineral peat soils } & $5-15$ & 0.35 & 0.45 & 79.8 & 37.3 \\
& $25-40$ & 0.2 & 0.3 & & 37.2 \\
Peat soils on hypnum peat & $5-15$ & 0.17 & 0.23 & 62.1 & 37 \\
& $25-40$ & 0.12 & 0.22 & & 38.6 \\
\hline
\end{tabular}

ble scales, as the integral geometry methods allow describing numerically the geometry of the intraaggregate pore space [46], as well as inter-aggregate and macroscopic pores [36].

Moreover, there are works that prove the relationship between the Minkowski functionals and some functional parameters of the media proper or of liquid flows in them $[9,14,28,45]$. Also noteworthy is the paper [24] investigating changes in the internal geometry of the pore space in oil collector on acidizing using the methods of integral geometry, as well as persistent homology theory.

In this work, we have applied the methodology of analyzing the internal geometry of pore space in various soil samples in dry and close to water saturation conditions in order to describe quantitatively the changes that go in soils [5, 7]. We have obtained tomographic images of several soil samples in the dry and water-saturated states. Unlike the works aimed at investigation of Minkowski functionals evolution in the course of erosion and dilatation of pore space, out study suggests using the morphological opening operation [33], which allows building cumulative and noncumulative distributions of Minkowski functionals by the pore sizes in the ordinary metric units. We also propose to analyze the Betty numbers of the pore space in addition to the Minkowski functionals, since they are rather vividly interpreted: the first Betty number corresponds to the quantity of individual pores, and the second Betty number corresponds to the amount of tunnels in the pore space of the soil sample.

\section{OBJECTS AND METHODS}

Soil samples. To assess the applicability of integral geometry, we have studied the soils contrasting in their origin, composition, and hydrophysical properties, i.e., agro-gray soil (Retic Phaeozem) and peat soil (Sapric Rheic Histosol). The samples differ radically in their structure changing upon interaction with water, which influences in different ways the volumetric indicators [23].

Low-moor peat was sampled in the Yakhroma River valley within the test plot of the Dokuchaev Soil Science Institute (Dmitrov district, Moscow oblast).

The peat soils within the test plot are subdivided into two types: reclaimed peat soils on mixed grass- hypnum and pure hypnum peat, enriched in carbonates (Rheic Sapric Histosols (Lignic)), and agromineral peat soils (Rheic Drainic Sapric Histosols (Mineralic)). Hypnum peat soils usually manifest a high natural moisture content and are treated as hardly drainable. Two factors control the genesis of peaty sites in the Yakhroma depression: the Yakhroma River (which flows quite close to the test plot), has formed agromineral peat soils during its floods; and a confined thick aquifer of ferruginous carbonate groundwater discharging in the near-terrace part of the Yakhroma valley. Agromineral peat (ash content 23\%) has developed under the influence of the Yakhroma River representing agromineral peat stratified soils (Fig. S1). Hypnum peat soils (ash content 16\%) enriched in carbonates have been formed on mixed grass-hypnum and hypnum peat (Fig. S2). Table 1 lists the peat soil properties in detail. These peats are specified by high natural moisture, and they are hardly drainable due to their dense-stemmed and loosened composition. The hypnum peat structure is composed of long-stemmed and branch-shaped leaf-like formations, which should have affected this soil behavior in wet and air-dry condition. Natural density is measured in a filled soil sample close to its natural state. The experimental density was reached by compaction of a peat column by tapping.

For the study, we have selected peats differing in their botanical composition, ash content, decomposition degree and other properties. The agro-gray soil was sampled at the Vladimirskoe Opolie on the Russian Plain northwest of Vladimir, on the high left bank of the Klyaz'ma River, to the southeast from the Moskovian glaciation edge. This territory is located in the zone of sufficient moistening, as an average longterm precipitation amounts to $575 \mathrm{~mm}$ and evaporation exceeds $400 \mathrm{~mm}$ per year there. The soils of the Vladimirskoe Opolie are mainly represented by agrogray forest soils (Retic Phaeozem, WRB 2014, version 2015) [41]. Some physical properties of these soils are listed in Table 2. The particle-size distribution in Retic Phaeozem samples was studied by laser diffraction with the Analysette 22 comfort (FRITCH, Germany) particle-size laser analyzer. The soil bulk density, field water capacity, filtration coefficient, and the ash content and decomposition degree of peat were determined by routine methods $[7,8]$. 
Table 2. Some physical properties of agro-gray soil

\begin{tabular}{|c|c|c|c|c|c|c|}
\hline \multirow{2}{*}{ Horizon, depth, cm } & \multicolumn{3}{|c|}{ Particle-size distribution, $\mathrm{mm}$} & \multirow{2}{*}{ Density, $\mathrm{g} / \mathrm{cm}^{3}$} & \multirow{2}{*}{$\mathrm{FWC}^{*}, \%$ mass } & \multirow{2}{*}{$\begin{array}{c}\text { Filtration } \\
\text { coefficient, } \mathrm{cm} / \text { day }\end{array}$} \\
\hline & $<0.002$ & $0.002-0.05$ & $>0.05$ & & & \\
\hline \multirow[t]{3}{*}{ Ap, $0-21$} & 17.39 & 80.66 & 1.95 & 1.1 & 37.3 & 60 \\
\hline & 17.35 & 80.21 & 2.44 & 1.16 & 37.2 & 58 \\
\hline & 17.21 & 80 & 2.79 & 1.21 & 37 & 52 \\
\hline \multirow[t]{2}{*}{ Asub, 21-37 } & 17.03 & 81.62 & 1.75 & 1.33 & 38.6 & 26 \\
\hline & 16 & 82.43 & 1.57 & 1.36 & 38.2 & 32 \\
\hline \multirow[t]{2}{*}{$\mathrm{AB}, 37-57$} & 17.35 & 81.76 & 0.89 & 1.33 & 37.4 & 35 \\
\hline & 17.32 & 82.09 & 0.59 & 1.39 & 35.3 & 35 \\
\hline B2, 72-96 & 18.4 & 81.1 & 0.5 & 1.4 & 37.6 & 28.5 \\
\hline
\end{tabular}

* Field water capacity.

In the studied agro-gray soils, a plow sole (subsoil compaction) appears from a depth of 20-30 $\mathrm{cm}$ (at a depth of 20-40 cm), which passes deeper into horizons compacted by evolutionary soil processes. Compaction does not exceed the critical levels for loamy agrosoils (up to $1.4 \mathrm{~g} / \mathrm{cm}^{3}$ ) [18], however, the difference is significant as compared to the arable horizons with the optimal density. Note that this phenomenon is specific for heavy loamy soils intensely used in farming.

For laboratory tomographic study, two monolithic samples of agro-gray soil were selected, as well as the samples of agromineral and hypnum peat soils. The samples were placed in cylindrical X-ray transparent cuvettes $16 \mathrm{~mm}$ in diameter and $40 \mathrm{~mm}$ high. The tomographic shooting of soils was performed using a SkyScan 1172 microtomograph (Belgium) at the Dokuchaev Soil Science Institute. The pore space was visualized with a CTvox (C) Bruker software (based on segmentation data and calculation of local pore thickness) for peat soils and ImageJ for agro-gray soils.

Sample saturation with water and $\mathrm{X}$-ray computer microtomography. The tomographic shooting was carried out for the samples in two conditions, i.e., in the air-dry condition and moistened to the state close to the minimal moisture capacity. For this purpose, the air-dry sample after tomographic shooting was moistened with the extra moisture through several layers of filter paper from the bottom for 7 days, water being constantly added to form a persistent water topping above the paper substrate. Next, the sample was kept to be drained free on a sandy substrate to reach a constant weight without evaporation; afterwards it was scanned on a tomograph for $2-3 \mathrm{~h}$. Before the tomography, the sample was sealed with a polyethylene film to exclude water evaporation during shooting and structure shrinkage deformation caused by evaporation. The shooting parameters were chosen proceeding from the operation protocols for similar soil samples, analyzed by tomography earlier [20, 25, 32, 44].

Tomographic shooting provides us with the sample images in the form of three-dimensional arrays of real numbers, which correspond to the absorption capacity of voxel substance of $8 \times 8 \times 8 \mu \mathrm{m}$ in size at each specific point of the soil sample. In the course of input data reconstruction, we come up with horizontal sections in the form of a data stack (TIFF files), permitting us either to build sections of any spatial direction or to segment the pore space.

The analysis of tomographic data elucidates the difference between a dry and a swollen sample even in flat (vertical and horizontal) sections. Swelling deforms the soil and reduces the pore volume at the expense of meso- and macropores, which can be seen in the sections without any mathematical processing. Fig. 1 shows 2D tomographic images of one dry and water-saturated sample. Pore space reduction is observed visually in the saturated sample (black) due to an increase in soil volume (gray) and darkening color, which points to a lower X-ray absorption upon identical shooting settings. Changes in the pore space structure are visible at a qualitative level: some flat fractures have closed, and the round-shaped pores became narrower.

However, processing of flat sections only does not show the complete pattern of changes in the pore space on swelling; this may be obtained upon processing volumetric data with a quantitative description of geometric and topological properties.

Minkowski functionals and Betty numbers. Let $X$ be an object (pore or pore space) bounded by a surface $\delta X$ in a 3-dimensional space $E=X^{3}$. To describe the geometric and topological properties of such a body, integral geometry allows us to define 4 topological invariants, i.e., Minkowski functionals [21, 30]. These functionals do not change under a continuous transformation of the body (homeomorphism) (Fig. 2).

In this work, we consider 3D tomographic images of soil samples. Pore space is taken as the object of research, since its structure largely determines the soil properties [2, 4, 20]. In this case, the Minkowski functionals with an accuracy to a factor correspond to the pore volume $\left(M_{0}\right)$, the pore surface area $\left(M_{1}\right)$, and the 
(a)

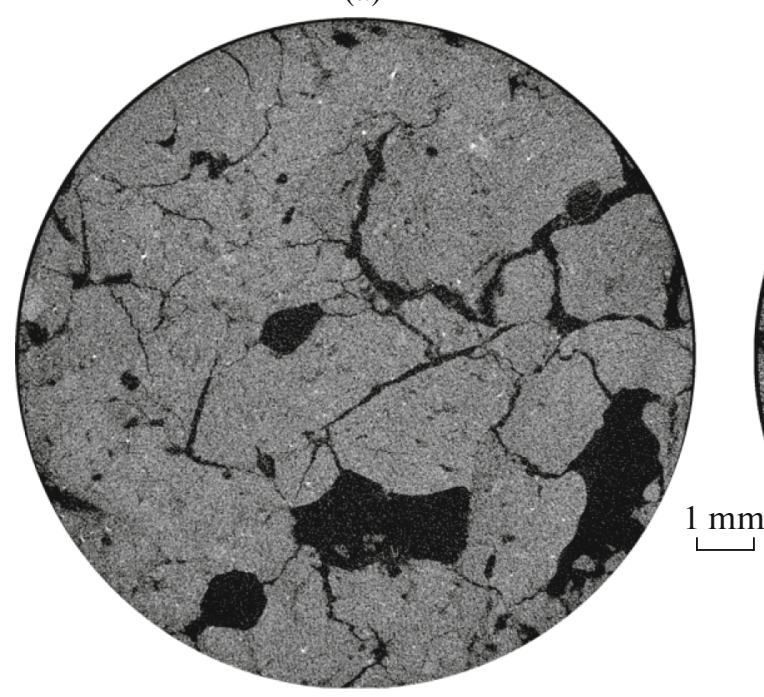

(b)

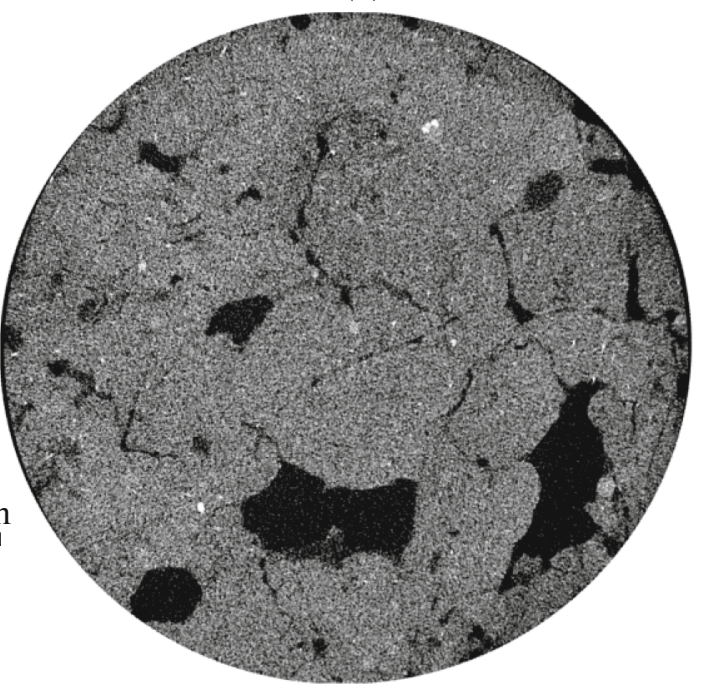

Fig. 1. Horizontal tomographic section of one agro-gray soil sample from the depth of $30-40 \mathrm{~cm}$ in the (a) dry and (b) wet states.

(a)
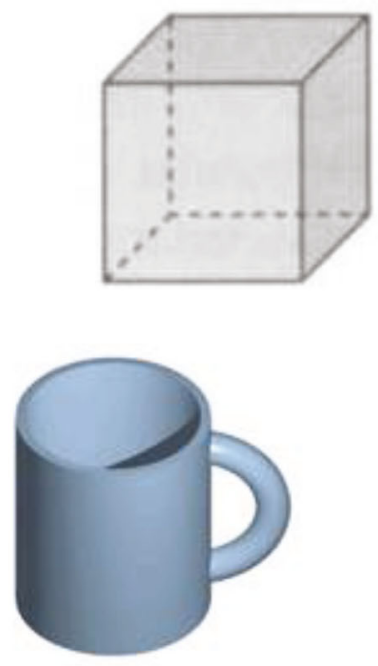

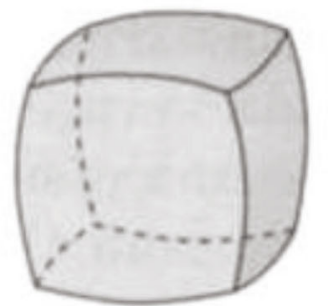

(b)
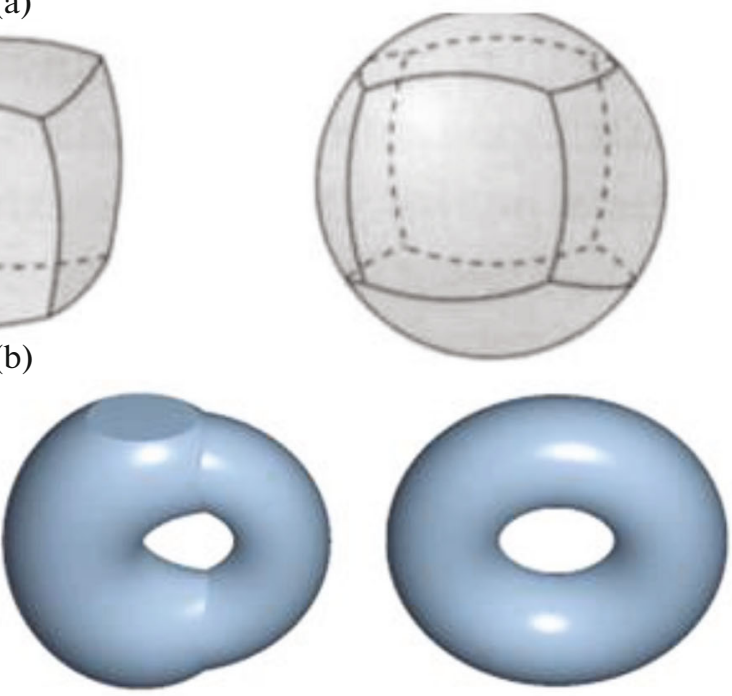

Fig. 2. Homeomorphic bodies: (a) without discontinuity (a sphere); and (b) with one discontinuity (a torus).

integral average curvature of the "pore-solid-phase skeleton" interface $\left(M_{2}\right)$, as well as the Euler-Poincaré characteristic of the pore space $\left(M_{3}\right)$ [10]:

$$
\begin{gathered}
M_{0}(X)=V(X), \quad M_{1}(X)=\int_{\delta X} d S=S(X), \\
M_{2}(X)=\int_{\delta X}\left(\frac{1}{r_{1}}+\frac{1}{r_{2}}\right) d S=C(X), \\
M_{3}(X)=\int_{\delta X} \frac{1}{r_{1} r_{2}} d S=2 \pi \chi(\delta X)=4 \pi \chi(X),
\end{gathered}
$$

where $r_{1}$ and $r_{2}$ are the principal radii of the surface curvature $d S$, and $\chi(\delta X)$ and $\chi(X)$ are the Euler-
Poincaré characteristics for the surface $\delta X$ and the convex body $X$, respectively. In order to avoid attributing the functional values to a specific sample, hereinafter we use their specific values for the computational area volume. This means that if the tomographic image resolution is $1000 \times 1000 \times 1000$ voxels, the values of functionals are divided by $10^{9}$.

The Euler-Poincaré characteristic for a convex body $X$ is an integral value of the topological complexity of the studied body and can be defined as a signalternating sum of Betti numbers:

$$
\chi(X)=b_{0}(X)-b_{1}(X)+b_{2}(X),
$$


where the Betti numbers may be interpreted as follows: $b_{0}$ is the number of separate pores (openings that do not stretch outside the sample), which are topologically homeomorphic to a sphere (Fig. 2a) also be a closed pore of a shape either and are always closed pores; $b_{1}$ (tunnels) is a number characterizing the quantity of bonds in the pore space. These are, for example, through (tunnel) pores with more than one exit outside the sample (the more exits, the greater the number $b_{1}$ ). This can topologically homeomorphic to a torus (Fig. 2b) or even more complicated (a double torus increases the number $b_{1}$ by 2 , a triple torus by 3 , etc.). The higher is $b_{1}$ value, the more branched the pore space is. The number $b_{2}$ stands for the amount of clusters of solid phase connectivity surrounded by voids; $b_{2}$ should be equal to one, since solid clusters (except for the sample proper) cannot be completely surrounded by voids.

Note that if there are only two phases (pores and a solid skeleton) in the analyzed sample, then by calculating the Minkowski functionals and the Betti numbers for one phase, the corresponding values for the second phase can be determined analytically.

Algorithms. A 3D image of pore space can be represented as a cubic cell combination, i.e., a 3D map built of voxels (3D pixels). Geometric and topological properties of cubic complexes is studied by digital topology. There are several algorithms permitting us to calculate the values of Minkowski functionals [26, 30, 39]. Paper [39] proposes an algorithm based on calculating the number of different local configurations $2 \times 2 \times 2$ voxels; whereas, paper [30] considers an algorithm based on counting the number of vertices, edges, faces and voxels in a cubic complex:

$$
\begin{gathered}
V(X)=n_{c}, \quad S(X)=-6 n_{c}+2 n_{f}, \\
2 C(X)=3 n_{c}-2 n_{f}+n_{e}, \\
\chi(X)=-n_{c}+n_{f}-n_{e}+n_{v},
\end{gathered}
$$

where $n_{c}$ is the number of voxels, $n_{f}$ is the number of faces, $n_{e}$ is the number of edges, and $n_{v}$ is the number of vertices in a cubic cell complex corresponding to the pore space in the sample. In our study, we used the software [27] for calculating the Minkowski functionals. The zero and the second Betty numbers (numbers of connected clusters in the pore space and the solid matrix) were calculated using the basic functions of MATLAB and ImageJ [38].

The additivity of the Minkowski functionals permits implementing the combinatorial algorithms for their computation, which do not require any significant computing resources and allow parallel computing in case the original image is of a high resolution.

The morphological opening operation used in this work is referred to a class of methods named mathematical morphology. The classic mathematical morphology was proposed in [40], where the main morphological operations were introduced: erosion (narrowing) (Fig. S3A) and dilatation (expansion) (Fig. S3B), as well as derived operations, i.e., opening and closing. After binarization, the resulting three-dimensional soil image consists of void voxels and solid-phase voxels. The morphological operation of dilation applied to void space converts solid-phase voxels at the pore/solid-phase boundary into void ones, thus "expanding" pores in this case. Erosion operation, on the contrary, converts void voxels at the boundary of void space to solid-phase voxels "narrowing" the pores. The voxel layer thickness changing after these operations is controlled by the structural unit "sliding" along the phase boundary. The opening operation combines the sequential erosion and dilation operations for the same structural element. Mathematical morphology has been often used for the analysis of soil tomographic images [36, 37, 45]. A detailed overview of the morphological analysis methods and their applicability to the study of two- and three-dimensional images of natural structures is provided in [31].

Fig. S4 shows the result of applying the "opening" morphological operation with an increasing diskshaped structural unit to the soil pore space image [27]. Due to these operations, we can calculate the functionals for pores of various diameters. Deriving such distributions of functionals for the pore space of samples in dry and wet conditions will allow us to describe quantitatively the transformations in the pore space structure in the course of soil saturation with moisture.

\section{RESULTS AND DISCUSSION}

Detailed analysis of monolithic samples. Let us consider the distributions of Minkowski functionals and Betti numbers by the pore sizes by the example of a soil sampled from the subplow A horizon at a depth of 30$40 \mathrm{~cm}$. Its pore space image is shown in Fig. 3, and the second sample is depicted in Fig. S5. The analysis of dependencies shown in the graphs (Fig. S6-S12) proves that after water saturation, the total porosity of the sample has decreased within the entire visible range of pore sizes, as did the specific pore surface area. The integral mean curvature of pore space decreases only in the range $<0.4 \mathrm{~mm}$, which is explained by the closure of small pores (with a large specific surface curvature). Large pores and fractures decrease in size only slightly and do not change their shape at all; therefore, their curvature is modified insignificantly.

Variation in the pore space structure upon different soil status is manifested in the distribution of the Euler-Poincaré characteristic $(\chi)$ and Betty numbers. The $\chi$ value shows the difference between $b_{0}$ and $b_{1}$, which stands for the topological complexity of structure: the greater its absolute value, the more one pore type prevails over another. The higher negative value of Euler-Poincaré parameter $\chi$, designates the greater amount of branched, coherent and interconnected pores in relation to isolated, topologically simple (spheres) pore structures. The $(\chi)$ parameter was neg- 


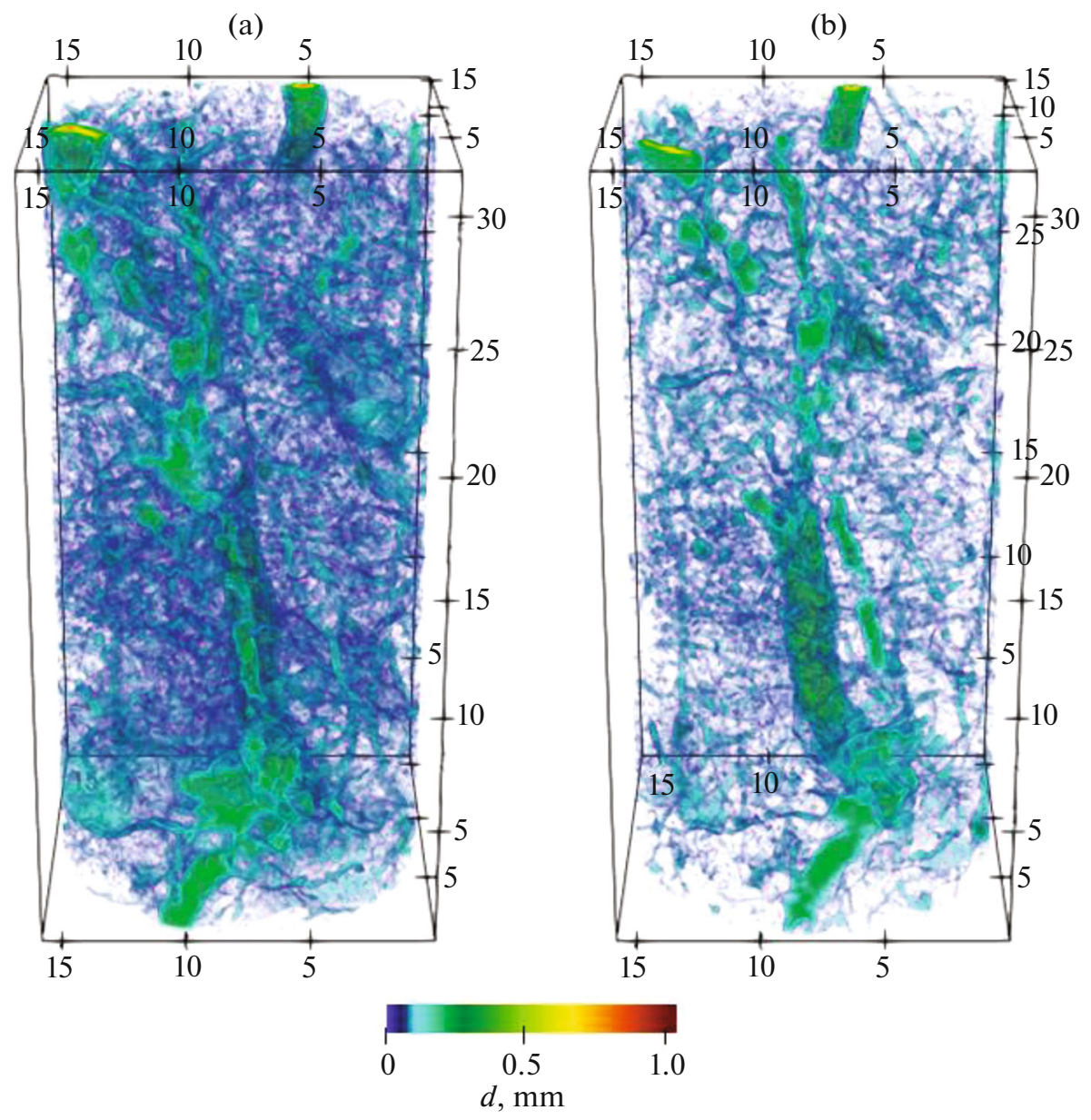

Fig. 3. The pore space visualization for the agro-gray soil, sample 1, taken at the depth of $30-40 \mathrm{~cm}$ from the subplow A horizon in the (a) dry and (b) liquid-saturated conditions. The Euclidian distance to the solid phase is marked in color. Pores colored in blue and green are less than $0.2 \mathrm{~mm}$ in diameter.

ative for the agromineral peat soil sample upon its saturation with water (Fig. S13). The reverse case is observed upon large positive $\chi$ values: topologically simple, isolated and closed pores predominate in the sample, the hypnum peat soil being the example (Fig. S15). However, it is worth considering zero and the first Betty numbers separately, since if both numbers $b_{0}$ and $b_{1}$ change equally, the Euler-Poincaré characteristic remains constant; however, it turns to zero for the similar values of Betty numbers.

For sample 1 of agro-gray soil, the Euler-Poincaré characteristic (Fig. S17) of the pore space decreases on soil swelling within the entire pore size range, i.e., the pore space becomes topologically better connected. This is confirmed by the analysis of Betty numbers, which can be vividly interpreted: the zero Betty number corresponds to the number of clusters of the pore interconnectedness, and the first Betty number stands for the number of tunnels in the solid phase. Isolated pores $\left(b_{0}\right)$ are empty spaces without exits beyond the sample boundaries. They are topologically homeomor- phic to a sphere and are always closed. Tunnels $\left(b_{1}\right)$ represent either open pores with more than one exit outside the sample (through pores), or closed pores of a shape topologically homeomorphic to a torus. The distribution analysis shows that a dry sample contains a greater number of both individual pores and tunnels as compared to the wet one, the difference being mainly manifested in the range $<0.4 \mathrm{~mm}$. In this case, the number of closed and topologically simple pores is reduced more than tunnels: $b_{0}^{\mathrm{dry}}-b_{0}^{\mathrm{wet}}>b_{1}^{\mathrm{dry}}-b_{1}^{\text {wet }}$.

The discrepancy between the values of the zero Betty number (Fig. 4a) in the water-saturated sample is registered for a larger range of pores than that of the first Betty number (Fig. 4b). This fact suggests that the swelling forces exert a greater influence on the tunnel and branched pores of a diameter exceeding $0.3 \mathrm{~mm}$. The number of isolated closed pores of this diameter remains the same upon saturation of agro-gray forest soil samples.

The second Betty number is predictably equal to one (it fits the number of solid phase connectivity 

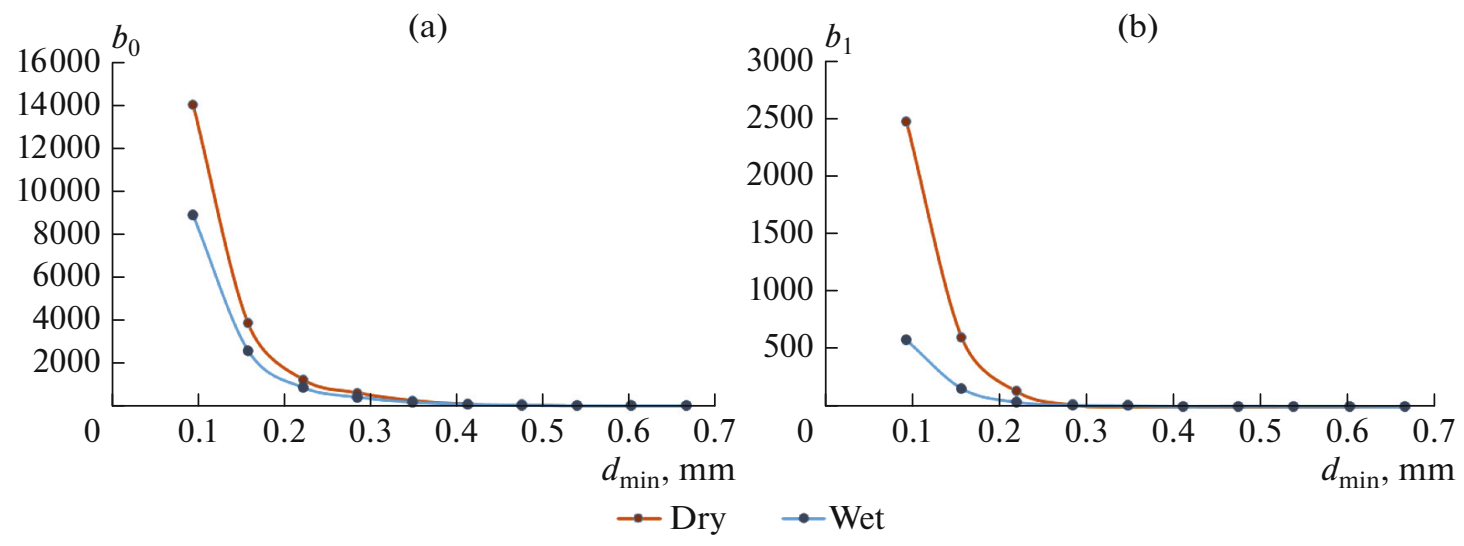

Fig. 4. Dependencies of the Betti numbers: (A) zero number $\left(b_{0}\right)$; (B) the first number $\left(b_{1}\right)$ on the pore size for the sample $30-$ $40 \mathrm{~cm}$, the subplow A horizon, agro-gray soil in dry (brown) and water-saturated (blue) conditions. Values $b_{0}$ and $b_{1}$ are represented by the relationship to the minimal pore diameter.

(a)

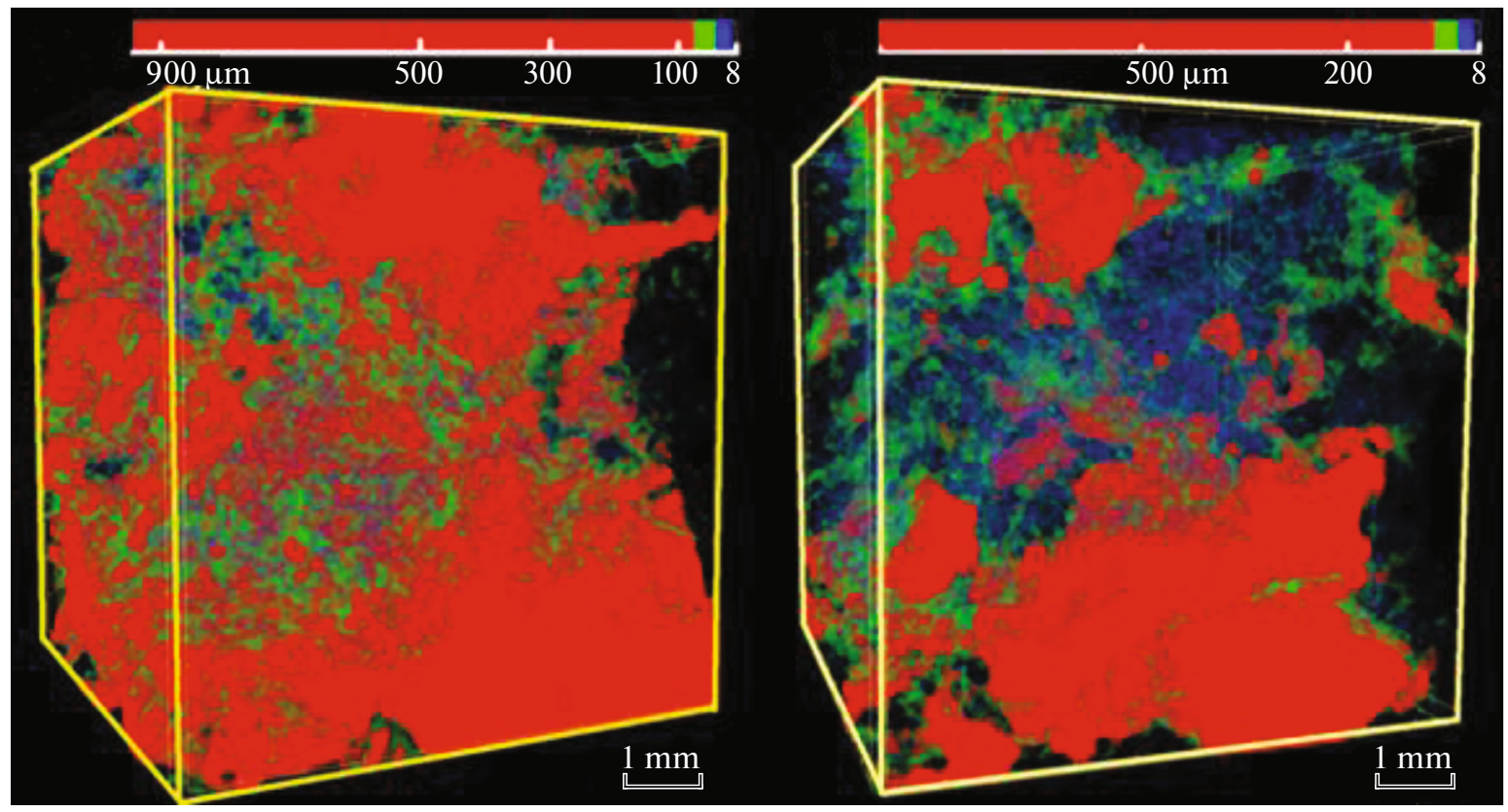

Fig. 5. The pore space visualization for the agromineral peat soil sample in the (a) dry and (b) water-saturated conditions. Pore sizes vary from 8 to $940 \mu \mathrm{m}$ (the largest pore). Color designates the pore size; pores $>70 \mu \mathrm{m}$ are shown in red.

clusters that are completely surrounded by empty space), being not shown in the graphs. It can be seen that a part of fine pores and channels present in the dry sample image (left) disappears in the wet sample image (right). Large pores and channels are reduced in size but remain in the wet sample image.

Upon saturation of the agromineral peat soil sample (visualized in Fig. 5), the number $b_{0}$ does not change, which points to the constant amount of isolated (unconnected) closed pores. The increased value of $b_{1}$ number may indicate the formation of voids filled with water in the solid organic phase. According to the changes in the Euler Poincaré characteristic, we may state the predominance of isolated closed pores over tunnels in a dry sample in the range of diameters $<0.2 \mathrm{~mm}$; however, upon water saturation, their amount becomes almost equal due to an increase in the number of tunnels and pore space bonds.

In the hypnum peat soil sample (visualized in Fig. S2), both Betti numbers decreased proportionally, and the Euler-Poincaré characteristic in a dry and saturated sample showed similar values over the entire range of 
pore diameters. For the structure of hypnum peat in low-moor bogs, consisting of long-stem residues, the swelling forces were sufficient to close both individual pores and tunnels, unlike the subplow horizon of agrogray soil, where tunnels were closed to a greater extent during saturation.

\section{CONCLUSIONS}

The methodological fundamentals of the numerical description of the soil pore space are provided based on the methods of integral geometry, topology and mathematical morphology. Changes in the soil pore space are numerically demonstrated upon soil saturation with liquid. As the object of the study, we used the agro-gray soil sampled at Vladimir opolie with an undisturbed structure and peat soils of various composition. For each sample, a tomographic image was obtained for dry and water-saturated states. A sample of agromineral peat soil showed a mobile structure, in which the volume, number and connectivity of pores with a diameter $<0.2 \mathrm{~mm}$ in the water-saturated sample increased due to reduction of the same indices for larger pores (with a diameter $>0.2 \mathrm{~mm}$ ). Proceeding from the $b_{0}$ and $b_{1}$ values (Fig. S14), we may conclude that such structural transformations in the agromineral peat soil sample take place at the expense of involved interconnected tunnel pores, characterized by $b_{1}$, whereas $b_{0}$ has almost the same values in the entire range of diameters in wet and dry conditions. Upon water saturation, large individual pores and branched tunnels disappeared in the samples of hypnum mosses, which can be judged by the change in Betty numbers (Fig. S16). This points to significant transformations in the pore pattern due to a decreasing cohesion of the pore space and the total pore volume. The Euler-Poincaré characteristic in dry and saturated samples had similar values over the entire range of pore diameters.

To describe quantitatively the transformations occurring in the pore space, we traced the evolution of the Minkowski functionals and Betti numbers in the course of increasing the structural unit size used in morphological opening operation. The results prove that this methodology can be used for describing quantitatively both the pores space pattern of soil samples and the structure transformations caused by any external forces or processes.

\section{ACKNOWLEDGMENTS}

Tomographic analysis was performed at the Center for Collective Use of Scientific Equipment "Functions and Properties of Soils and Soil Cover" at the Dokuchaev Soil Science Institute.

\section{FUNDING}

This work was partially supported by the Russian Foundation for Basic Research, project 19-29-05112_mk "Digi- tal Physics and Hydrology of Soils: The Basics of SpatialDynamic Analysis, Predicting the Risks of Critical Situations and Optimal Management."

\section{CONFLICT OF INTEREST}

The authors declare that they have no conflicts of interest.

\section{OPEN ACCESS}

This article is licensed under a Creative Commons Attribution 4.0 International License, which permits use, sharing, adaptation, distribution and reproduction in any medium or format, as long as you give appropriate credit to the original author(s) and the source, provide a link to the Creative Commons license, and indicate if changes were made. The images or other third party material in this article are included in the article's Creative Commons license, unless indicated otherwise in a credit line to the material. If material is not included in the article's Creative Commons license and your intended use is not permitted by statutory regulation or exceeds the permitted use, you will need to obtain permission directly from the copyright holder. To view a copy of this license, visit http://creativecommons.org/licenses/by/4.0/.

\section{SUPPLEMENTARY INFORMATION}

The online version contains supplementary materials available at DOI: 10.1134/S1064229321090039 and accessible for authorized users.

Figs. S1, S2. Visualization of the pore space of agromineral peat (S1) and hypnum peat (S2) samples: (a) in the dry sample and (b) in the water-saturated sample. Pore size varies from 8 to $940 \mu \mathrm{m}$ (the largest pore). The color indicates the pore size; pores $>70 \mu \mathrm{m}$ are colored in red.

Fig. S3. The result of applying operations: (a) erosion, (b) dilatation with the structural units of different sizes to the image of soil pore space. The voids are shown in white, the solid phase in black.

Fig. S4. An example of applying the morphological opening operation with the structural unit of different size to the image of soil pore space. The voids are shown in white, the solid phase in black. This operation results in a series of images showing only the pores of size exceeding that of structural unit.

Fig. S5. Visualization of the pore space in the sample 2 of agro-gray soil at a depth of $30-40 \mathrm{~cm}$ from the subplow horizon A in (a) and (b) liquid-saturated conditions. Colors show the Euclidean distance to the solid phase. Blue-green pores do not exceed $0.2 \mathrm{~mm}$ in diameter.

Figs. S6-S9. Cumulative (S6, S8) and differential (S7, S9) dependencies between the specific pore volume V and the pore size for agro-gray soil, samples no. 1 (S6, S7) and no. $2(\mathrm{~S} 8, \mathrm{~S} 9)$, taken at a depth of $30-40 \mathrm{~cm}$ from the subplow A horizon in wet (blue) and dry (brown) states.

Figs. S10A, S10B. Differential dependencies between the integral average curvature of the surface $\mathrm{C}$ and the pore size in agro-gray soil, samples 1 and 2, taken at a depth of 
$30-40 \mathrm{~cm}$ from the subplow A horizon in wet (blue) and dry (brown) states.

Figs. S11, S12. Cumulative dependencies between the surface area $\mathrm{S}$ and the pore size for agro-gray soil, samples 1 and 2, taken at a depth of 30-40 cm from the subplow A horizon in wet (blue) and dry (brown) states.

Figs. S13, S15, S17. Dependences of the Euler-Poincaré characteristic $(\chi)$ on the minimum pore diameter for agromineral peat soil (S13), hypnum peat soil (S15) in dry condition (brown) and agro-gray soil, sample 1 (S17) in water-saturated (blue) condition.

Fig. S14. Dependencies of the Betty numbers, i.e., zero number $\left(b_{0}\right)$ and the first number $\left(b_{1}\right)$ on the minimum pore diameter for agromineral (S14) and hypnum (S16) peat soils in dry (brown) and water-saturated (blue) conditions.

\section{REFERENCES}

1. A. L. Ivanov, E. V. Shein, and E. B. Skvortsova, "Tomography of soil pores: from morphological characteristics to structural-functional assessment of pore space," Eurasian Soil Sci. 52, 50-57 (2019).

2. E. Yu. Milanovskii, E. V. Shein, and A. A. Stepanov, "Liophilic-liophobic properties of organic matter and the structure of soils," Pochvovedenie, No. 6, 122-126 (1993).

3. E. B. Skvortsova and N. V. Kalinina, "Micromorphometric types of the pore space in virgin and plowed loamy soils," Eurasian Soil Sci. 37, 980-991 (2004).

4. E. B. Skvortsova, V. A. Rozhkov, K. N. Abrosimov, K. A. Romanenko, S. F. Khokhlov, D. D. Khaidapova, V. V. Klyueva, and A. V. Yudina, "Microtomographic analysis of pore space in a virgin soddy-podzolic soil," Eurasian Soil Sci. 49, 1250-1258 (2016).

5. V. M. Sorochkin, "The choice of indicators for agronomic assessment of soil structure," Pochvovedenie, No. 7, 50-58 (1991).

6. V. M. Sorochkin, "Equilibrium density of sod-podzolic soils and its change during processing," Pochvovedenie, No. 2, 129 (1982).

7. E. V. Shein, Course of Soil Physics (Moscow State University, Moscow, 2005) [in Russian].

8. Theories and Methods of Soil Physics, Ed. by E. V. Shein and L. O. Karpachevskii (Grif i K, Moscow, 2007) [in Russian].

9. T. Akai, Q. Lin, A. Alhosani, B. Bijeljic, and M. J. Blunt, "Quantification of uncertainty and best practice in computing interfacial curvature from complex pore space images," Materials 12 (13), 2138 (2019). https://doi.org/10.3390/ma12132138

10. C. Arns, M. Knackstedt, and N. Martys, "Cross-property correlations and permeability estimation in sandstone," Phys. Rev. E 72 (4), 046304 (2005). https://doi.org/10.1103/PhysRevE.72.046304

11. C. H. Arns, M. A. Knackstedt, and K. R. Mecke, "Characterization of irregular spatial structures by parallel sets and integral geometric measures," Colloids Surf., A 241 (1-3), 351-372 (2004).

https://doi.org/10.1016/j.colsurfa.2004.04.034
12. Y. Bazaikin, B. Gurevich, S. Iglauer, T. Khachkova, D. Kolyukhin, M. Lebedev, V. Lisitsa, and G. Reshetova, "Effect of CT image size and resolution on the accuracy of rock property estimates: effect of CT image scale," J. Geophys. Res.: Solid Earth 122, 3635-3647 (2017). https://doi.org/10.1002/2016JB013575

13. Y. Bazaikin, B. Gurevich, S. Iglauer, T. Khachkova, D. Kolyukhin, M. Lebedev, V. Lisitsa, and G. Reshetova, "Effect of CT image size and resolution on the accuracy of rock property estimates: effect of CT image scale," J. Geophys. Res.: Solid Earth 122, 3635-3647 (2017). https://doi.org/10.1002/2016JB013575

14. C. F. Berg, "Permeability description by characteristic length, tortuosity, constriction and porosity," Transp. Porous Media 103 (3), 381-400 (2014). https://doi.org/10.1007/s11242-014-0307-6

15. A. Çeçen, E. A. Wargo, A. C. Hanna, D. M. Turner, S. R. Kalidindi, and E. C. Kumbur, "3-D microstructure analysis of fuel cell materials: spatial distributions of tortuosity, void size and diffusivity," J. Electrochem. Soc. 159 (3), 299-307 (2012). https://doi.org/10.1149/2.068203jes

16. J. Fan, B. McConkey, H. Wang, and H. Janzen, "Root distribution by depth for temperate agricultural crops," Field Crops Res. 189, 68-74 (2016). https://doi.org/10.1016/j.fcr.2016.02.013

17. B. A. Faybishenko, "Hydraulic behavior of quasi-saturated soils in the presence of entrapped air: Laboratory experiments," Water Res. Res. 31 (10), 2421-2435 (1995). https://doi.org/10.1029/95WR01654

18. Y. Feng, J. Wang, T. Liu, Z. Bai, and L. Reading, "Using computed tomography images to characterize the effects of soil compaction resulting from large machinery on three-dimensional pore characteristics in an opencast coal mine dump," J. Soils Sediments. 19 (3), 1467-1478 (2019). https://doi.org/10.1007/s11368-018-2130-0

19. K. M. Gerke, E. B. Skvortsova, and D. V. Korost, "Tomographic method of studying soil pore space: current perspectives and results for some Russian soils," Eurasian Soil Sci. 45, 700-709 (2012).

20. S. N. Gorbov, K. N. Abrosimov, O. S. Bezuglova, E. B. Skvortsova, and S. S. Tagiverdiev, "Microtomography research of physical properties of urban soil," IOP Conf. Ser.: Earth Environ. Sci. 368, 012015 (2019).

21. H. Hadwiger, Vorlesungen Über Inhalt, Oberfläche und Isoperimetrie (Springer-Verlag, Berlin, 1957).

22. V. Hallaire and P. Curmi, "Image analysis of pore space morphology in soil sections, in relation to water movement," Dev. Soil Sci. 22, 559-567 (1993).

23. E. V. Shein, A. D. Pozdnyakova, A. P. Shvarov, L. I. Il'in, and N. V. Sorokina, "Hydrophysical properties of the high-ash lowmoor peat soils," Eurasian Soil Sci. 51, 1214-1219 (2018). https://doi.org/10.1134/S1064229318100113

24. T. S. Khachkova, Ya. V. Bazaikin, and V. V. Lisitsa, "Use of the computational topology to analyze the pore space changes during chemical dissolution," Num. Methods Program. 21, 41-55 (2020).

https://doi.org/10.26089/NumMet.v21r104 
25. D. D. Khaidapova, V. V. Klyueva, E. B. Skvortsova, and K. N. Abrosimov, "Rheological properties and tomographically determined pore space of undisturbed samples of typical chernozems and soddy-podzolic soils," Eurasian Soil Sci. 51, 1191-1199 (2018).

26. D. Legland, K. Kiêu, and M.-F. Devaux, "Computation of Minkowski measures on 2D and 3D binary images," Image Anal. Stereol. 26, 83 (2011). https://doi.org/10.5566/ias.v26.p83-92

27. D. Legland, K. Kiêu, and M.-F. Devaux, "Computation of Minkowski measures on 2D and 3D binary images," Image Anal. Stereol. 26, 83 (2011).

28. J. E. McClure, R. T. Armstrong, M. A. Berrill, S. Schlüter, S. Berg, W. G. Gray, and C. T. Miller, "Geometric state function for two-fluid flow in porous media," Phys. Rev. Fluids 3 (8), (2018).

https://doi.org/10.1103/PhysRevFluids.3.084306

29. K. R. Mecke and H. Wagner, "Euler characteristic and related measures for random geometric sets," J. Stat. Phys. 64 (3), 843-850 (1991). https://doi.org/10.1007/BF01048319

30. K. Michielsen and H. De Raedt, "Integral-geometry morphological image analysis," Phys. Rep. 347 (6), 461-538 (2001). https://doi.org/10.1016/S0370-1573(00)00106-X

31. J. Ohser and K. Schladitz, 3D Images of Materials Structures: Processing and Analysis (Wiley, Weinheim, 2009). ISBN 978-3-527-62830-8

32. T. Romanis, S. Sedov, S. Lev, M. Lebedeva, K. Kondratev, A. Yudina, K. Abrosimov, A. Golyeva, and D. Volkov, "Landscape change and occupation history in the Central Russian Upland from Upper Palaeolithic to medieval: paleopedological record from Zaraysk Kremlin," Catena 196, 104873 (2021).

33. K. A. M. Said, A. B. Jambek, and N. Sulaiman, "A study of image processing using morphological opening and closing processes," Int. J. Control Theory Appl. 9 (31), 15-21 (2016).

34. F. San José Martínez, L. Martín, and C. García-Gutiérrez, "Minkowski functionals of connected soil porosity as indicators of soil tillage and depth," Front. Environ. Sci. 6, 55 (2018). https://doi.org/10.3389/fenvs.2018.00055

35. F. San José Martínez, F. J. Muñoz Ortega, F. J. Caniego Monreal, A. N. Kravchenko, and W. Wang, "Soil aggregate geometry: measurements and morphology," Geoderma 237-238, 36-48 (2015)).

https://doi.org/10.1016/j.geoderma.2014.08.003

36. F. San José Martínez, F. J. Muñoz Ortega, F. J. Caniego Monreal, and F. Peregrina, "Morphological functions to quantify three-dimensional tomograms of macropo- re structure in a vineyard soil with two different management regimes," Vadose Zone J. 12 (3), (2013).

https://doi.org/10.2136/vzj2012.0208

37. F. San José Martínez, F. J. Muñoz Ortega, F. J. Caniego Monreal, and F. Peregrina, "Morphological functions with parallel sets for the pore space of X-ray CT images of soil columns," Pure Appl. Geophys. 173 (3), 9951009 (2014). https://doi.org/10.1007/s00024-014-0928-2

38. J. Schindelin, C. T. Rueden, M. C. Hiner, and K. W. Eliceiri, "The Image J ecosystem: an open platform for biomedical image analysis," Mol. Reprod. Dev. 82 (7-8), 518-529 (2015).

39. K. Schladitz, J. Ohser, and W. Nagel, "Measuring intrinsic volumes in digital 3D images," in Discrete Geometry for Computer Imagery (Springer-Verlag, Berlin, 2006), Vol. 4245, pp. 247-258. ISBN 978-3-540-47651-1

40. J. Serra, Image Analysis and Mathematical Morphology (Academic, London, 1982). ISBN 978-0-12-637240-3

41. E. V. Shein, V. I. Kiryushin, A. A. Korchagin, M. A. Mazirov, A. V. Dembovetskii, and L. I. Il'in, "Assessment of agronomic homogeneity and compatibility of soils in the Vladimir Opolie region," Eurasian Soil Sci. 50, 1166-1172 (2017).

https://doi.org/10.1134/S1064229317100118

42. E. V. Shein and O. A. Troshina, "Physical properties of soils and the simulation of the hydrothermal regime for the complex soil cover of the Vladimir Opol'e region," Eurasian Soil Sci. 45, 968-976 (2012).

https://doi.org/10.1134/S1064229312100092

43. E. B. Skvortsova and N. V. Kalinina, "Micromorphometric types of the pore space in virgin and plowed loamy soils," Eurasian Soil Sci. 37, 980-991 (2004).

44. E. B. Skvortsova, V. A. Rozhkov, K. N. Abrosimov, K. A. Romanenko, S. F. Khokhlov, D. D. Khaidapova, V. V. Klyueva, and A. V. Yudina, "Microtomographic analysis of pore space in a virgin soddy-podzolic soil," Eurasian Soil Sci. 49, 1250-1258 (2016).

45. H.-J. Vogel, U. Weller, and S. Schlüter, "Quantification of soil structure based on Minkowski functions," Comput. Geosci. 36, 1236-1245 (2010). https://doi.org/10.1016/j.cageo.2010.03.007

46. W. Wang, A. N. Kravchenko, A. J. M. Smucker, W. Liang, and M. L. Rivers, "Intra-aggregate pore characteristics: X-ray computed microtomography analysis," Soil Sci. Soc. Am. J. 76, 1159-1171 (2012). https://doi.org/10.2136/sssaj2011.0281

Translated by $O$. Eremina 